\title{
Position Compensation Method of BLDC Motor for Automotive Applications
}

\author{
Jun-Hyuk Choi ${ }^{1,2}$, Joon Sung Park ${ }^{1}$ and Chung-Yuen Won ${ }^{2}$ \\ ${ }^{I}$ Korea Electronics Technology Institute \\ ${ }^{2}$ University of Sungkyunkwan
}

\begin{abstract}
Because of recent environmental issues, national fuel efficiency regulations are being strengthened and the market demand for high efficiency vehicle is increasing. In order to improve the fuel efficiency, it is needed to improve the efficiency of the combustion engine or to reduce the losses. Brushless dc (BLDC) motor has a number of advantages such as high efficiency, high power factor, and low maintenance cost. The motor for automotive applications should be made compact and increasing the efficiency causing limited automotive volume. However it is difficult to control precisely BLDC motors with hall sensors. Because it is difficult for the hall sensors to be positioned exactly 120 electrical degrees apart. BLDC control with unbalanced hall sensors cause the current ripple and torque ripple. Sensor-less configuration may be inappropriate for all automotive applications, because of the slow response speed and difficult operating at low speed. This paper deals primarily with the design aspects of the permanent magnet brushless dc motor and method of measuring rotor position using hall sensors.
\end{abstract}

Keywords - brushless dc (BLDC) motor, inverter, hall sensor, position estimation

\section{INTRODUCTION}

Over the several years, demands for fuel efficiency and low emissions have become strict. To meet these needs, mechanical methods are being replaced with the power electronic methods in the automotive application. DC motors have ever been prominent in various industrial applications. because their characteristics and controls are simple. In an industrial point of view, the dc motor is still more than others at low power ratings. However, dc motor drives have bulky construction, low efficiency, low reliability and need of maintenance. Those features are unsuitable for automotive applications. In recent years, the brushless dc (BLDC) motor is attracting growing attention for automotive applications. This is due to the total elimination of the brush/commutator assembly, which reduces audible noise and RFI problems. Moreover, BLDC motor has a number of advantages such as high efficiency, high power factor, and low maintenance cost. The motor for automotive applications should be made compact and increasing the efficiency causing limited automotive volume and battery capacity. Based on the technological growth of electric machines and power electronics, the trend in the automotive industry is to replace conventional dc motor with BLDC motor based on electric motor technology [1]-[4]. A BLDC motor consists of permanent magnet synchronous machine supplied with an inverter. In this type of motor the switching logic of the inverter is determined by rotor position. Generally, the approaches to establish the rotor position may be classified into sensor and sensor-less method [7]. The method that uses hall sensors has numerous advantages, especially at low speeds where many sensor-less methods become less accurate.

The theory of BLDC control has been well investigated in the literature [2]-[6]. Most of the publications on BLDC assume that hall sensors are positioned exactly 120 electrical degrees apart. This assumption may not be true for many low cost and low precision motors that are mass produced on the market [7]. Linear hall sensors give better resolution than discrete ones. However linear hall sensors are less cost competitive. Various approaches of the alignment for discrete hall sensors have been developed [7]-[12]. Most of approaches are based on a vector-tracking observer [11], [12] and filtering [7]-[10]. These methods have good performance. These approaches allow the relative positions of the hall sensors are electrically 120 degrees apart. However, the absolute position of the hall sensors can be different for each of the models. This is the important point for mass-production. We present in this paper a simple methodology for detecting absolute position of a BLDC motor using 8-bit processor and back-emf.

The remainder of this paper is organized as follows. Section II presents 120 degrees commutation control theory of a BLDC motor based on discrete hall sensors. Section III presents position estimation method with block commutation based on hall sensors. Section IV presents experimental results. Finally, Section V concludes the paper with some remarks. 


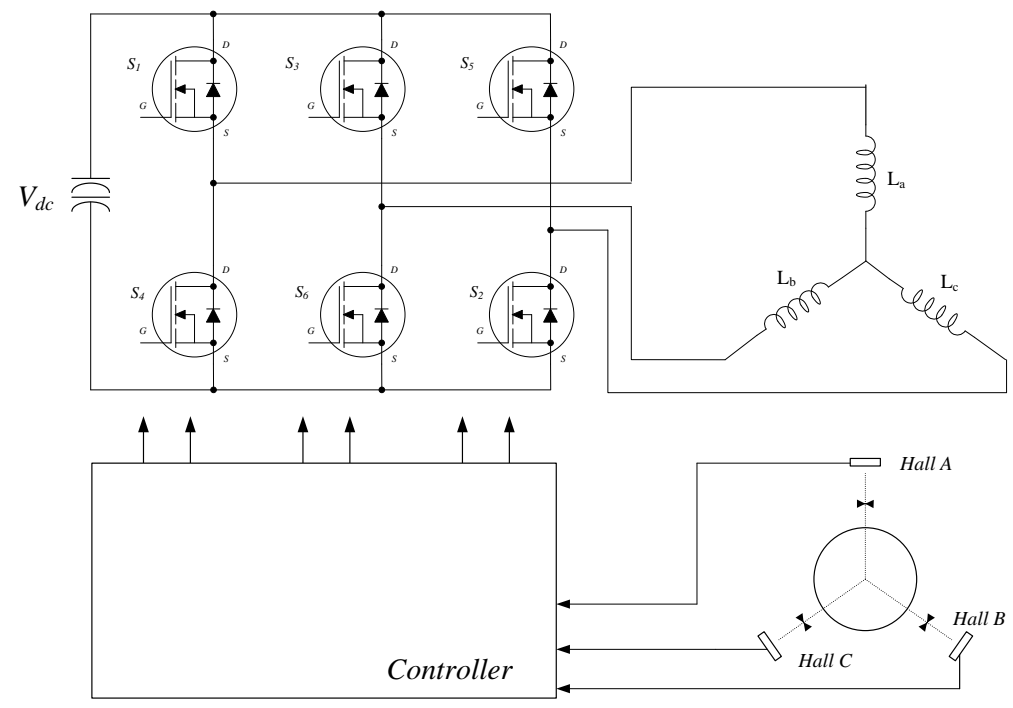

Figure 1. Control diagram of BLDC motor using hall sensors.

\section{MODELING OF BLDC MOTOR}

A disadvantage in brush-type motors is their inherent brush and commutator requirement. A BLDC motor eliminates the brush and commutator assembly and operates indirectly from DC. Unlike the brush motor, whose armature resides on the rotor, the BLDC motor carries magnets. The BLDC motor is popular for many types of applications that cannot tolerate brushes and in equipment that requires good speed control plus high power efficiency [3]. Usually, the BLDC motor is operated by hall sensors. Most of the literatures assume that hall sensors are positioned exactly 120 degrees apart. This assumption may not be true for many low precision motors that are mass-produced on the market. The automotive motor is also one of them. With the misplaced hall sensors, it is difficult to adequately control torque, because magnet torque and reluctance torque cycle is different. In the case of a great torque ripple in the motor is a cause of mechanical fatigue, noise and vibration.
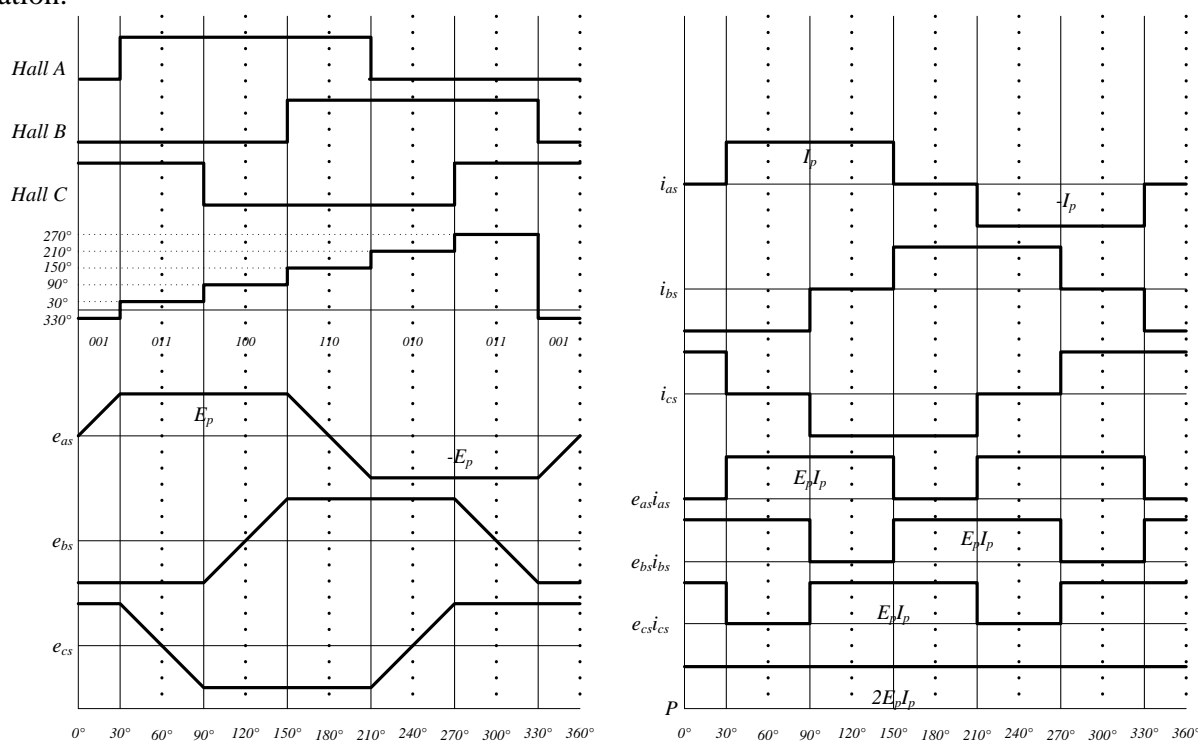

Figure 2. BLDC motor waveforms.

The block diagram of BLDC motor drive is shown in Figure 1. The coupled circuit equations of the stator winding in terms of motor electrical constants are

$$
\left[\begin{array}{c}
V_{a s} \\
V_{b s} \\
V_{c s}
\end{array}\right]=\left[\begin{array}{ccc}
R_{s} & 0 & 0 \\
0 & R_{s} & 0 \\
0 & 0 & R_{s}
\end{array}\right]\left[\begin{array}{l}
i_{a s} \\
i_{b s} \\
i_{c s}
\end{array}\right]+\frac{d}{d t}\left[\begin{array}{c}
\lambda_{a s} \\
\lambda_{b s} \\
\lambda_{c s}
\end{array}\right]
$$

where $R_{s}$ is the stator resistance per phase, assumed to be equal for all three phases. The induced emfs $e_{a s}, e_{b s}, e_{c s}$ are all assumed to be trapezoidal. 


$$
\left[\begin{array}{l}
V_{a s} \\
V_{b s} \\
V_{c s}
\end{array}\right]=\left[\begin{array}{ccc}
R_{s} & 0 & 0 \\
0 & R_{s} & 0 \\
0 & 0 & R_{s}
\end{array}\right]\left[\begin{array}{l}
i_{a s} \\
i_{b s} \\
i_{c s}
\end{array}\right]+\left[\begin{array}{ccc}
L_{a a} & L_{a b} & L_{a c} \\
L_{b a} & L_{b b} & L_{b c} \\
L_{c a} & L_{c b} & L_{c c}
\end{array}\right] \frac{d}{d t}\left[\begin{array}{c}
i_{a s} \\
i_{b s} \\
i_{c s}
\end{array}\right]+\left[\begin{array}{l}
e_{a s} \\
e_{b s} \\
e_{c s}
\end{array}\right]
$$

If there is no change in the rotor reluctance with angle because of a non-salient rotor, and assuming three symmetric phases, the following are obtained.

$$
L_{a a}=L_{b b}=L_{c c}, L_{a b}=L_{a c}=L_{b a}=L_{c a}=L_{b c}=L_{c b}=M
$$

Substituting equation (3) in equation (2) gives the BLDC motor model as

$$
\left[\begin{array}{l}
V_{a s} \\
V_{b s} \\
V_{c s}
\end{array}\right]=R_{s}\left[\begin{array}{lll}
1 & 0 & 0 \\
0 & 1 & 0 \\
0 & 0 & 1
\end{array}\right]\left[\begin{array}{c}
i_{a s} \\
i_{b s} \\
i_{c s}
\end{array}\right]+\left[\begin{array}{ccc}
L & M & M \\
M & L & M \\
M & M & L
\end{array}\right] \frac{d}{d t}\left[\begin{array}{l}
i_{a s} \\
i_{b s} \\
i_{c s}
\end{array}\right]+\left[\begin{array}{c}
e_{a s} \\
e_{b s} \\
e_{c s}
\end{array}\right]
$$

The stator phase currents are constrained to be balanced, which leads to the simplification of the inductance matrix in the model as

$$
\left[\begin{array}{l}
V_{a s} \\
V_{b s} \\
V_{c s}
\end{array}\right]=R_{s}\left[\begin{array}{ccc}
1 & 0 & 0 \\
0 & 1 & 0 \\
0 & 0 & 1
\end{array}\right]\left[\begin{array}{c}
i_{a s} \\
i_{b s} \\
i_{c s}
\end{array}\right]+\left[\begin{array}{ccc}
L-M & 0 & 0 \\
0 & L-M & 0 \\
0 & 0 & L-M
\end{array}\right] \frac{d}{d t}\left[\begin{array}{c}
i_{a s} \\
i_{b s} \\
i_{c s}
\end{array}\right]+\left[\begin{array}{c}
e_{a s} \\
e_{b s} \\
e_{c s}
\end{array}\right]
$$

The electromagnetic torque is given by

$$
T_{e}=\left[e_{a} i_{a}+e_{b} i_{b}+e_{c} i_{c}\right] \frac{1}{\omega}
$$

Assuming that there is no phase difference between current and back-emf, we can write the electromagnetic torque as

$$
T_{e}=\frac{2 E I}{\omega}
$$

The interaction of $\mathrm{T}_{\mathrm{e}}$ with the load torque determines how the motor speed is built up

$$
T_{e}=T_{L}+J \frac{d \omega}{d t}+B \omega
$$

Where, $\mathrm{T}_{\mathrm{L}}$ is load torque, $\mathrm{J}$ is inertia, and $\mathrm{B}$ is the viscous damping.

Figure 2 shows hall sensor signal, back-emf and phase current waveforms, where the rotor is rotating in a counter clockwise direction. These current and emf waveforms have flat portion, which occurs for 120 electrical degrees. If the hall sensors are exactly placed 120 electrical degrees apart, the waveform of phase current is ideal and there is small torque ripple. However, the hall sensors could be misaligned. Figure 3 shows a cross section of a BLDC motor with misplaced hall sensors. $\mathrm{H} 1, \mathrm{H} 2$ and $\mathrm{H} 3$ denote the ideal sensors. H1', H2' and H3' represent the actual sensors. The quantities of $\phi_{\mathrm{a}}, \phi_{\mathrm{b}}$ and $\phi_{\mathrm{c}}$ denote the misplacement angles.

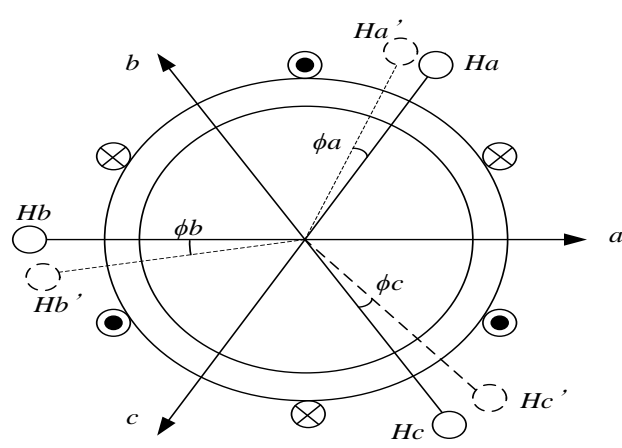

Figure 3. Cross-section of a BLDC motor.

Figure 4 shows unbalanced hall sensor signals and phase current. The commutation conduction logic of the inverter is very sensitive to the physical position of hall sensors. The insufficiently precise positioning of the hall sensors causes unbalanced operation of the inverter, with some phases conducting for longer and other phases conducting for shorter time intervals. The resulting unbalance among the phases leads to an increase in torque pulsation, vibration and audible noise [7]. 

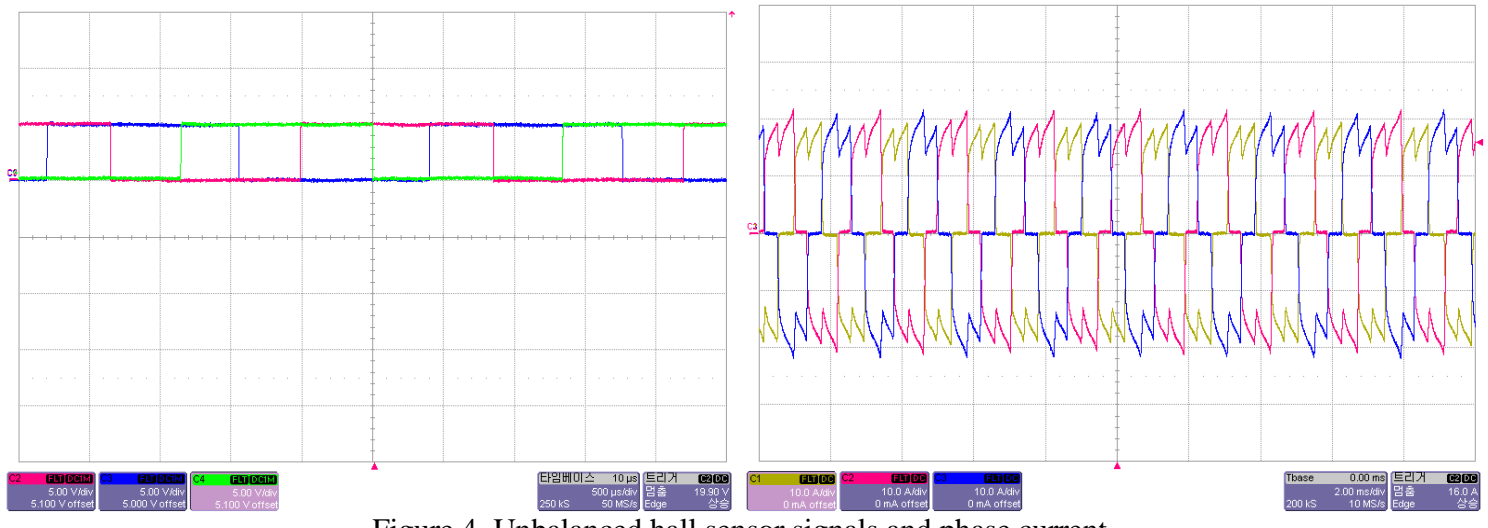

Figure 4. Unbalanced hall sensor signals and phase current.

\section{POSITION ESTIMATION BASED ON BACK-EMF}

Figure 5 shows comparison ideal and actual hall sensor signals. In this figure, the rotor position is transiently distorted at each state transition of the unbalanced hall sensors' signals. Assuming that the rotor speed within a sector is constant and the average speed in a current and previous sector is uniform, the time interval of the sector can be approximated as follows,

$$
\begin{aligned}
& \Delta t_{1}^{\prime}-\phi_{a}+\phi_{c}=\Delta t \\
& \Delta t_{2}^{\prime}-\phi_{c}+\phi_{b}=\Delta t \\
& \Delta t_{3}^{\prime}-\phi_{b}+\phi_{a}=\Delta t
\end{aligned}
$$

where $\Delta \mathrm{t}$ is the time interval of the previous sector and $\Delta \mathrm{t}_{1}{ }^{\prime}, \Delta \mathrm{t}_{2}{ }^{\prime}, \Delta \mathrm{t}_{3}{ }^{\prime}$ are actual time inter of the each sector. Then, the angle $\phi_{\mathrm{a}}, \phi_{\mathrm{b}}, \phi_{\mathrm{c}}$, can be described as follows.

$$
\begin{aligned}
& \phi_{a}=\phi_{a} \\
& \phi_{b}=\Delta t_{3}^{\prime}-\Delta t+\phi_{a} \\
& \phi_{c}=\Delta t-\Delta t_{1}^{\prime}+\phi_{a}
\end{aligned}
$$

When we get $\phi_{\mathrm{a}}$ the rest of the values can be calculated. The angle $\phi_{\mathrm{a}}$ can be obtained from back-emf.

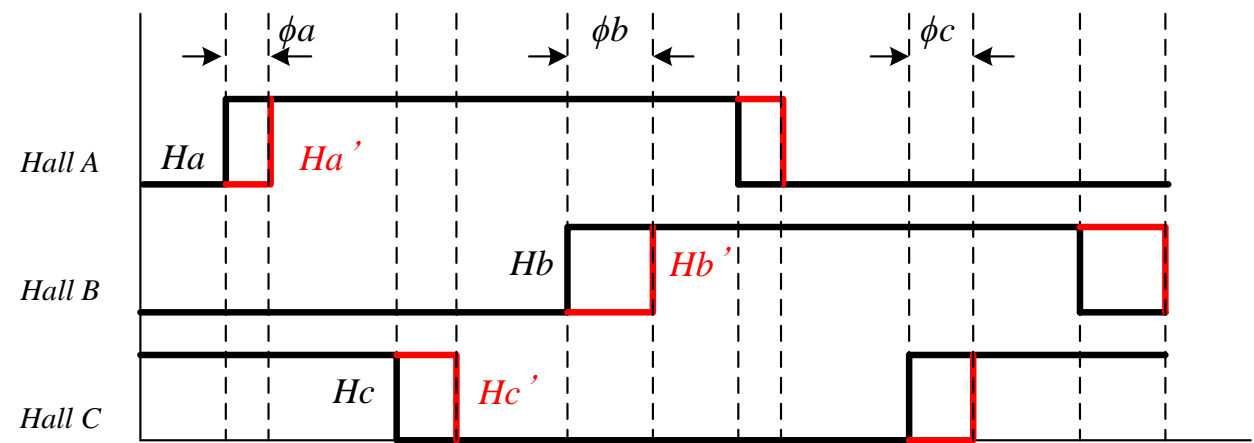

Figure 5. Comparison ideal and unbalanced hall sensor signals.

The motor for automotive application such as variable valve actuation (VVA) need to fast response, wide speed operation and forward, reverse operation. And also, it is needed to apply simple method for mass-production. By these reasons, it is difficult to apply linear position sensor method or sensor-less method. There is lots of sensor-less methods but they do not have good starting characteristics and they need some additional circuits and fast computational processor. And sensor-less method operating low speed is unstable. To overcome these problems, we present simple position estimation using discrete hall sensors and back-emf. 


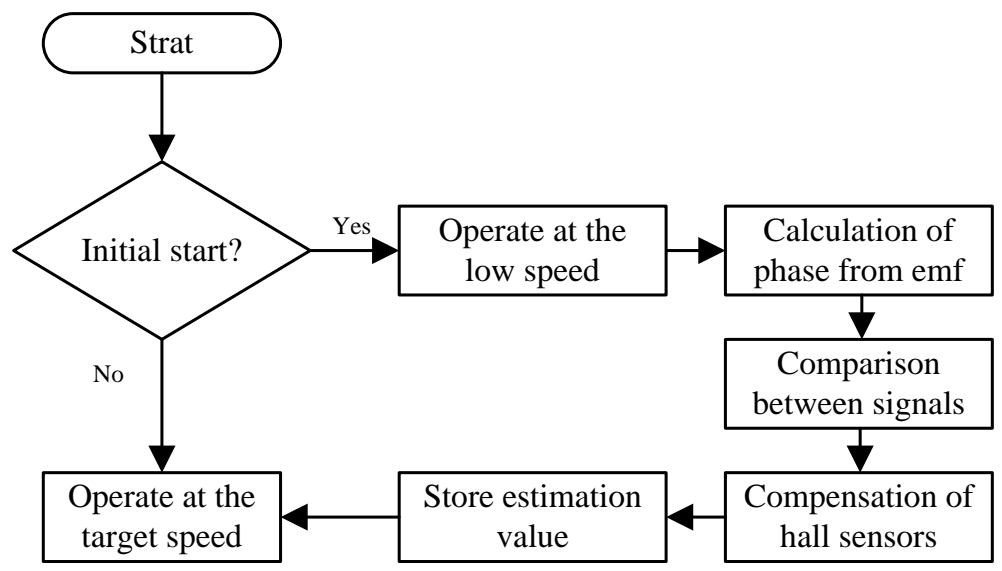

Figure 6. Flowchart of position estimation.

Figure 6 shows a flowchart of proposed BLDC control. At first time of starting the BLDC moto, it operates squarewave current motor with signal of hall sensors. This method is the way to control BLDC motor mostly. By comparing the hall sensor and back-emf signal, the phase difference between two signals is calculated. In order to reduce errors, it operates during the position estimation at a low speed. And it is difficult to find precise zero-crossing point of back-emf without additional circuit and high resolution processor. However a method that the angle is inferred from the back-emf is simple and does not need additional circuit. This estimation process is required only once and can be achieved in the production process.

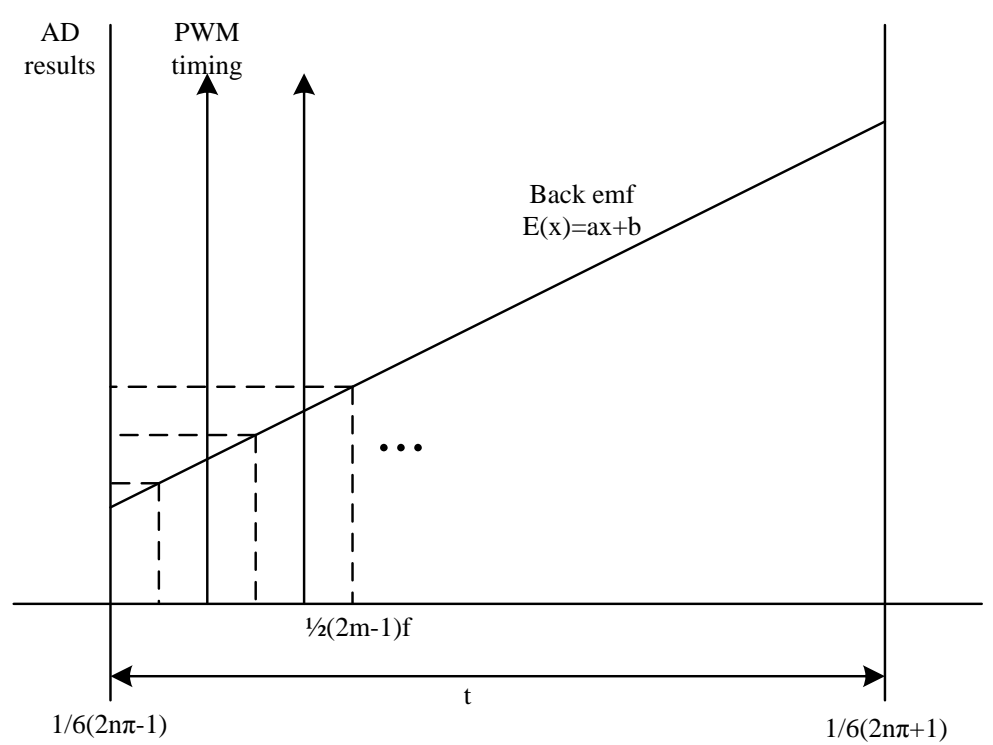

Figure 7. Position estimation at the constant speed.

Figure 7 shows position estimation method at sector $n$. The back-emf at the constant speed $(\omega)$ are

$$
E(x)=a x+b
$$

where $x$ is the time when processor reads back-emf signal and a, b are constant at the speed $\omega$. We use the center-aligned PWM mode. This type of PWM output uses the up/down counter. When the counter bits are all high, the ADC (Analogue to Digital Converter) is enabled. We can obtain degrees of back-emf easily from the equation (11). By comparing the hall sensor and back-emf signal, the phase difference between two signals can be calculated. 


\section{EXPERIMENTAL RESULTS}

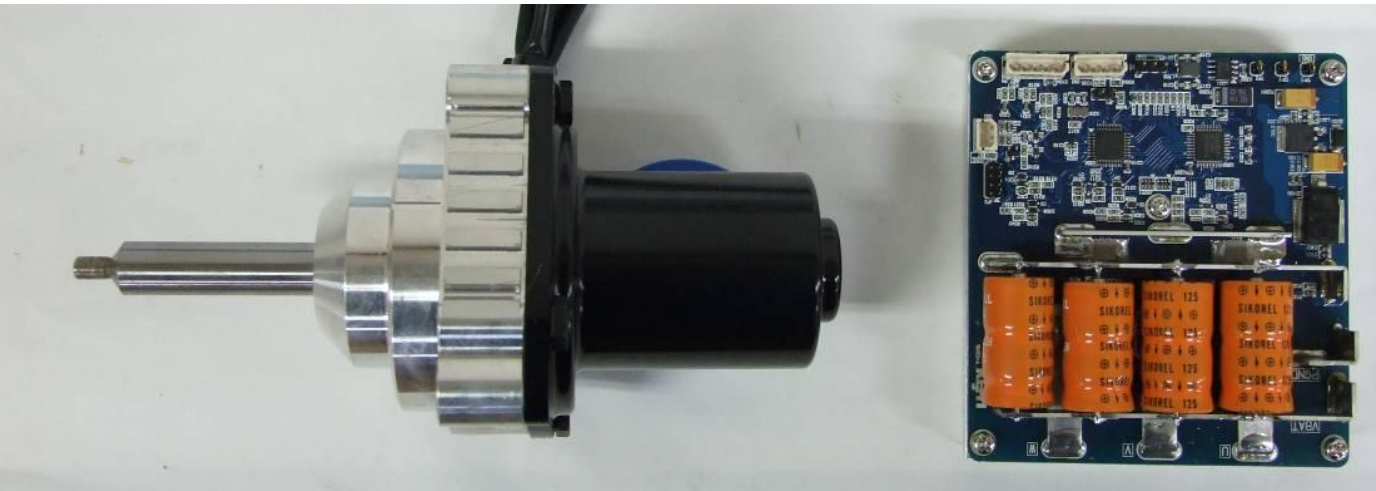

Figure 8. VVA module and drive.

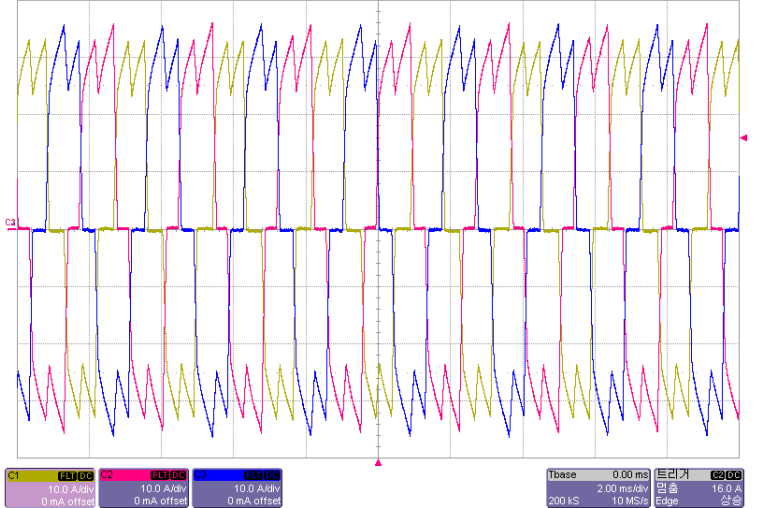

(a)Conventional method (350mNm, 6500rpm).

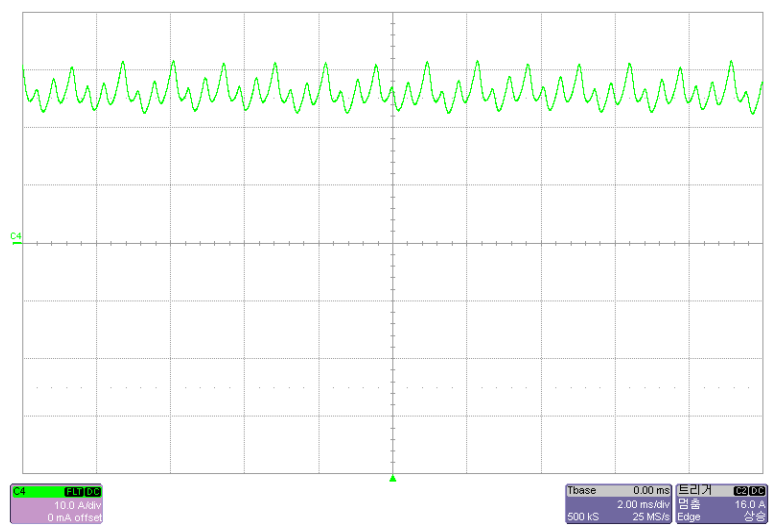

(c)Conventional method (350mNm, 6500rpm).

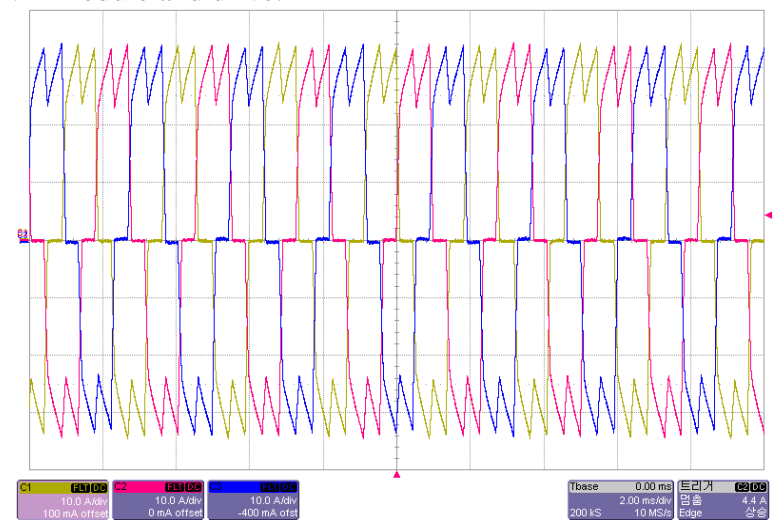

(b)Proposed method (350mNm, 6500rpm).

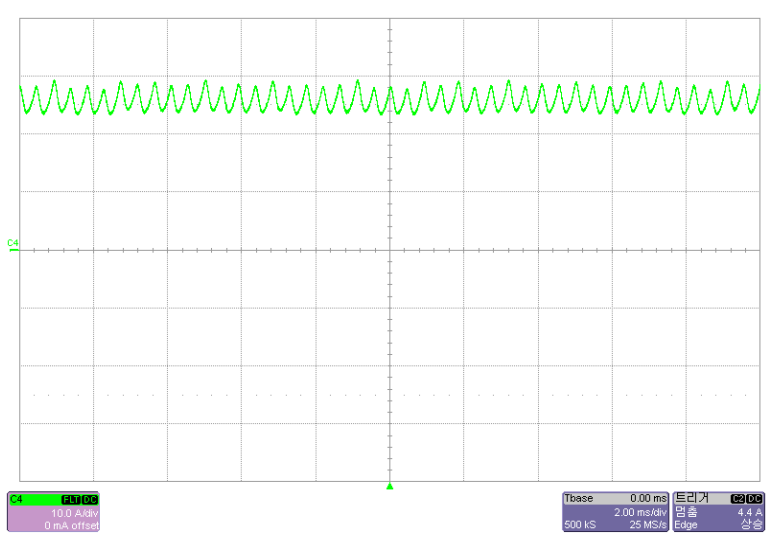

(d)Proposed method (350mNm, 6500rpm).

Figure 9. Input and output current waveforms.

Several experiments have been performed to validate the proposed rotor position estimator based on unbalanced hall sensors. Figure 8 shows photos of BLDC motor and drive for variable valve actuation (VVA) module. For the test, we selected VVA motor. In order to apply the VVA, the elements of the drive were selected by considering the environmental temperature, because the VVA module is located around the engine. The overall control scheme was implemented on 8 bit processor (XC886). The drive was tested extensively at $350 \mathrm{mNm}$. The specification of the drive is presented in table I.

TABLE I. Specification of the motor drive

\begin{tabular}{|l|l|c|}
\hline \multicolumn{1}{|c|}{ Items } & \multicolumn{1}{|c|}{ specification } & Unit \\
\hline Processor & XC886 (Infineon/8bit) & \\
\hline Nominal operating voltage & 13.5 & $\mathrm{~V}$ \\
\hline Operating voltage range & $9 \sim 18$ & $\mathrm{~V}$ \\
\hline Operating current range & $0 \sim 60$ & $\mathrm{~A}$ \\
\hline Operating temperature & $-40 \sim 125$ & ${ }^{\circ} \mathrm{C}$ \\
\hline Operating control & CAN communication & \\
\hline Operation monitoring & Voltage, current, temperature, speed & \\
\hline Protection & $\begin{array}{l}\text { Volatge, current, temperature, } \\
\text { reverse voltage, inrush current, speed }\end{array}$ & \\
\hline
\end{tabular}




\section{CONCLUSION}

In this paper, a position estimation with unbalanced hall sensors has been proposed. The proposed approach has a sensor-less algorithm, which has zero crossing point of back-emf. Even though we do not obtain $\phi_{\mathrm{a}}$, we can get the relative positions which are electrically 120 degrees apart. In order to obtain the absolute position of the hall sensors, we use the back-emf. The proposed scheme is simple and relatively accurate. For mass production, control scheme was implemented on 8 bit processor.

Through the experimental results, validity and quality of the reported designs are verified, and the drive is obtained reduced current ripple. The developed BLDC drive has been successfully applied to automotive application.

\section{REFERENCES}

[1] M. Zeraoulia, M. E. H. Benbouzid, and D.Diallo, Electric Motor Drive Selection Issues for HEV Propulsion Systems: A Comparative Study, Vehicular Technology, IEEE Trans. on, vol. 55, Issue 6, 2006, 1756-1764.

[2] T.J.E. Miller, and Hendershot, Design of Brushless Permanent-Magnet Motors, Magna Physics publishing and Clarendon Press, Oxford, 1994

[3] Richard Valentine, Motor Control Electronics Handbook (McGrow-Hill Handbook, 1998).

[4] Kwanghee Nam, AC Motor Control and Electric Vehicle Applications (CRC Press, 2010).

[5] P. C. Krause, O. Wasynczuk, and S. D. Sudhoff, Analysis of Electric Machinery and Drive Systems (IEEE Press, Piscataway, NJ, 2002).

[6] S. D. Sudhoff, and P. C. Krause, Operating modes of the brushless DC motor with a $120^{\circ}$ inverter, IEEE Trans. Energy Conversion, Vol. 5, No. 3, 1990, 558-564.

[7] Alaeinovin. P., Chiniforoosh. S, and Jatskevich. J, Evaluating misalignment of hall sensors in brushless DC motors, IEEE Elctric Power Conference, 2008, 1-6.

[8] Alaeinovin. P., and Jatskevich. J, Filtering of Hall-Sensor Signals for Improved Operation of Brushless DC Motors, IEEE Trans. Energy Conversion, Vol. PP, Issue 99, 2012, 1-3.

[9] Alaeinovin. P., and Jatskevich. J, Hall-sensor signals filtering for Improved Operation of Brushless DC Motors, IEEE ISIE, 2011, 613-618.

[10] Samoylenko. N, Qiang Han, and Jatskevich. J, Dynamic Performance of Brushless DC Motors With Unbalanced Hall Sensors, IEEE Trans. Energy Conversion, Vol. 23, Issue 3, 2008, 752-763.

[11] S. Y. Kim, C. Choi, K. Lee, and W. Lee, An Improved Rotor Position Estimation With Vector Tracking Observer in PMSM Drives With Low Resolution Hall-Effect Sensors, IEEE Trans. Industrial Electronics, Vol. 58, Issue 9, 2011, 4078-4086.

[12] F. Giulii Capponi, G. De Donato, L. Del Ferraro, O. Honorati, M. C. Harke, and R. D. Lorenz, AC brushless drive with low-resolution Hall-effect sensors for surface-mounted PM machines, IEEE Trans. Ind. Appl., vol. 42, no. 2, 2006, 526-535. 